\title{
Mandibular metastasis from a prostate adenocarcinoma: Report a case and review of the literature
}

\author{
Nasim Taghavi ${ }^{* 1}$, Fatemeh Mashhadiabbas ${ }^{1}$, Parisa Kardouni ${ }^{1}$, Farzad Aghdashi ${ }^{2}$ \\ ${ }^{1}$ Oral \& Maxillofacial pathology department, School of Dentistry, Shahid Beheshti University of Medical Sciences, Tehran, Iran \\ ${ }^{2}$ Oral \& Maxillofacial surgery department, School of Dentistry, Shahid Beheshti University of Medical Sciences, Tehran, Iran
}

Received: January 16, 2016

DOI: $10.5430 /$ jst.v6n1p91
Accepted: February 20, 2016

Online Published: March 1, 2016

\begin{abstract}
Metastasis to maxillofacial region is extremely rare and constitutes less than $1 \%$ of all oral malignancies. The mandible is the preferred site. Here, we describe the case of an 82-year-old male with mandibular metastasis from prostate carcinoma and review of 10 reported cases in the English literature up to 2016.
\end{abstract}

Key Words: Mandible, Metastasis, Prostate carcinoma

\section{INTRODUCTION}

Carcinoma of prostate accounts for $25 \%$ of all malignancies in male that tends to metastasize to bone. Ribs, ilium of pelvis, the vertebral column and skull are often involved, whereas less than $1 \%$ of malignant tumors metastasize to maxillofacial region. ${ }^{[1]}$ The mandible is the preferred site. The primary site differed between genders: for women it is the breast; for men it is the lung. ${ }^{[2]}$

This article describes details of an 82-year old male patient with mandibular metastasis from advanced prostate adenocarcinoma. Additionally, we reviewed 10 case reports of metastatic prostate adenocarcinoma to the mandible in the English literature up to 2016.

\section{Case presentation}

An 82-year old man was referred to the oral and maxillofacial surgery department, School of Dentistry, Beheshti University of Medical Sciences (Tehran, Iran) in September 2015, complaining of a mass on the right side of the mandible associated with pain and Parasthesia since 8 months before.
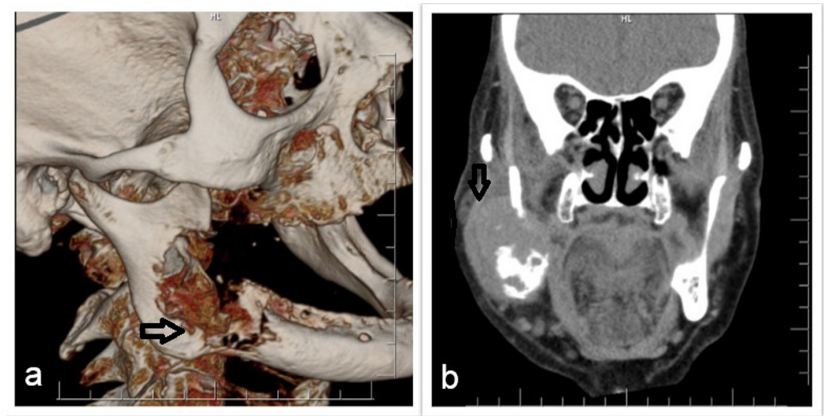

Figure 1. a) 3D image, b) coronal soft tissue algorithm view. Images show a lytic lesion (arrows) in the body and ramus of right mandible associated with mandibular canal destruction.

Intra-oral examination revealed remarkable expansion of right mandible with firm consistency measured about $4 \mathrm{~cm}$,

\footnotetext{
*Correspondence: Nasim Taghavi; Email: nasimtaghavi46@gmail.com; Address: School of Dentistry, Shahid Beheshti University of Medical Sciences, Tehran, Iran.
} 
causing facial asymmetry. Computed Tomography (CT) images showed a lytic lesion with severe bony destruction in body and ramus of right mandible and perforation of buccal and lingual table associated with mandibular canal destruction (see Figure 1). Review of past medical history presented an adenocarcinoma of prostate. In March 2014 he was investigated in department of urology for lower urinary tract symptoms and elevated serum prostate specific antigen (PSA) levels. Histopathologic analysis of prostate biopsy confirmed prostate adenocarcinoma with a Gleason score $4+4=8$. The patient was diagnosed with locally advanced tumor without any metastasis (pT3b N0M0) and was treated by radical prostectomy in April 2014.

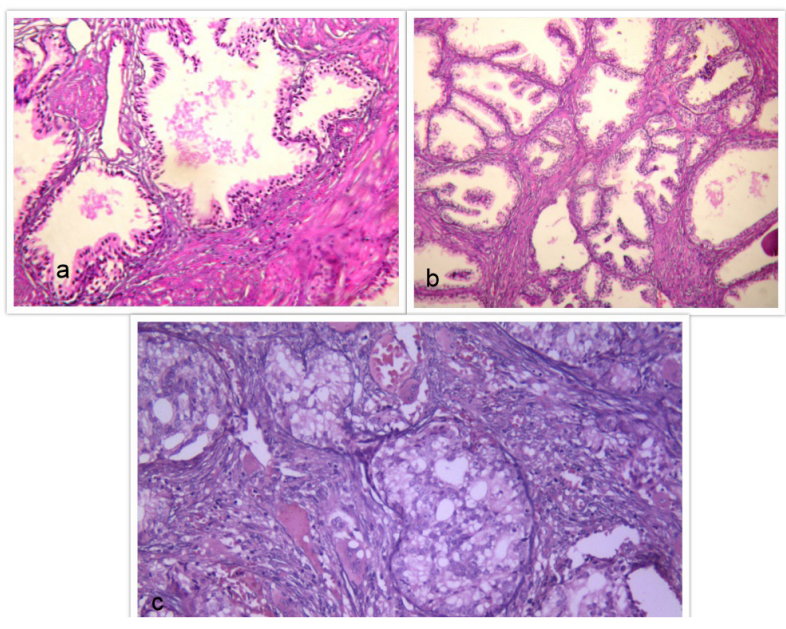

Figure 2. a, b) Tumoral cells with papillary pattern $(\times 100)$; c) Solid pattern with duct formation in some area $(\times 100)$

Regarding the strong possibility of prostate tumor metastasis as the first differential diagnosis, an incisional biopsy of hard and soft tissue was performed. Furthermore, prostate tumor pathology slides were requested for reevaluation. Histopathologic examination of mandibular lesion revealed columnar, cuboidal and clear cells with hyperchromatism, pleomorphism and mitotic activity, arranged in papillary and solid pattern with duct and cyst formation in some areas (see Figures 2 and 3) similar to prostate adenocarcinoma specimen.
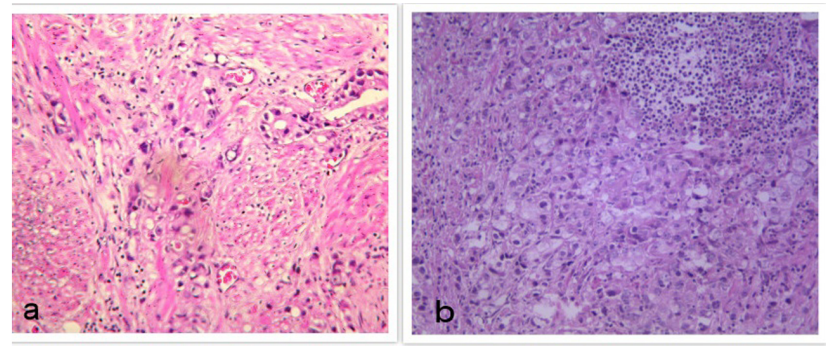

Figure 3. Atypical tumor cells with hyperchromatism and pleomorphism in solid pattern $(\times 200)$
So, the diagnosis of metastatic adenocarcinoma of prostate was confirmed. Considering extension and destruction of the lesion and also patient disability, treatment was limited to radiotherapy and palliation.

\section{DisCUSSION}

The skeleton is one of the most common sites for the metastasis. Metastatic tumor cells reach the bones through the complex arterial and venous system. Hematopoietically active marrow is an attractive location of metastasis involvement because of the sinusoidal structure of vascular space and easy barrier for penetration of tumor cells. ${ }^{[3]}$ Jaw bones, specifically in the elderly, are devoid of active marrow, but residue of hematopoietic marrow in the posterior part of mandible may act as a favorable pathway attracting metastatic tumor cells. ${ }^{[4-6]}$ Metastatic prostate tumors of mandible are extremely rare with only 10 reported cases in the English literature (see Table 1). It constitutes $5 \%$ of jaw metastatic diseases and $6 \%$ of mandibular metastatic tumors. ${ }^{[2]}$ The risk factors for disease dissemination and distant metastasis to skeleton include high histologic grade (Gleason's combined score $\geq 7$ ), high stage and pelvic lymph node metastasis. ${ }^{[1,6]}$

Previously reported cases predominantly occurred in the $7^{\text {th }}$ and $8^{\text {th }}$ decades of life just like the present case, mostly in molar region and rarely in condyle. ${ }^{[2,3,5,7]}$ The most common clinical characteristics of patients are swelling and pain which develops in a short time, but teeth mobility, parasthesia and limited mandibular movement have been reported. ${ }^{[8,9]}$

Radiographic feature usually presents as irregular radiolucency which typically occurs in poorly differentiated prostate carcinoma. ${ }^{[10]}$ However, inducing reactive new bone formation by tumor may produce sclerotic lesions which should be differentiated from fibro-osseous lesions. ${ }^{[10,11]}$ Despite the presence of clinical symptoms in metastatic tumors of maxillofacial region, radiographs do not show any radiographic changes in some cases and the diagnosis is made only by surgical exploration. ${ }^{[7,9]}$

Histophatologically, in typical cases, the unique morphologic features of well developed small glands of prostate carcinoma are easy to recognize in metastatic site. In addition, two specific markers, prostate specific antigen (PSA) and prostate specific acid phosphatase (PSAP) can be helpful for diagnosis. ${ }^{[2]}$ Of note, some poorly differentiated prostate carcinoma can be negative for both PSA and PSAP. Overall, the meantime between diagnosis of the primary tumor and discovery of metastatic jaw tumors including prostate carcinoma is about 40 months. Moreover, mean time from detecting of metastasis to death is 7.3 months representing a grave prognosis. ${ }^{[5,12]}$ 
Table 1. Previous literature documenting mandibular metastasis from prostate carcinoma

\begin{tabular}{llllll}
\hline NO & Source & Age & Symptom & Location & Side \\
\hline 1 & Cakmak et al. 2015 & 65 & Swelling & Molar area & Right \\
2 & Aksoy et al. 2014 & 78 & Pain/paresthesia & Molar area & Left \\
3 & Qui et al. 2013 & 85 & Swelling & Condyle & Right \\
4 & Freudlsperger et al. 2012 & 75 & Pain/opening limitation & Condyle & Left \\
5 & Vanderwal et al. 2003 & 90 & Swelling & NA & NA \\
6 & Vanderwal et al. 2003 & 74 & Swelling & NA & NA \\
7 & Vanderwal et al. 2003 & 64 & Swelling/pain & Molar area & NA \\
8 & Pruckmayer et al. 1996 & 62 & Swelling/pain & Molar area & Right \\
9 & Catrambone et al. 1995 & 78 & Swelling & Condyle & Right \\
10 & Thatcher et al. 1986 & 68 & Swelling & Condyle & Left \\
\hline
\end{tabular}

Note. NA, not available.

In conclusion, metastasis of prostate carcinoma to the mandible is a rare event which predominantly occurs in older age and mostly in molar area. The most common symptoms are rapid growing mass and pain. The prognosis is poor as more than two thirds of the patients die within a year.

\section{CONFLICTS OF INTEREST Disclosure}

The author declares that there is no conflict of interest statement.

\section{REFERENCES}

[1] Bubendorf L, Schöpfer A, Wagner U, et al. Metastatic patterns of prostate cancer: an autopsy study of 1,589 patients. Hum Pathol. 2000 May; 31(5): 578-83. PMid:10836297. http://dx.doi.org $/ 10.1053 / \mathrm{hp} .2000 .6698$

[2] Çakmak Ö, Tarhan H, Küçük Ü, et al. Prostatic adenocarcinoma with initial metastatic spread to the mandible. Turk J Urol. $2015 \mathrm{Sep}$; 41(3): 149-51. PMid:26516599. http://dx.doi.org/10.5152/t ud. 2015.36043

[3] Freudlsperger C, Kurth R, Werner MK, et al. Condylar metastasis from prostatic carcinoma mimicking temporomandibular disorder: a case report. Oral Maxillofac Surg. 2012 Mar; 16(1): 7982. PMid:21125304. http://dx.doi.org/10.1007/s10006-0 10-0256-3

[4] Pruckmayer M, Glaser C, Nasel C, et al. Bone metastasis with superimposed osteomyelitis in prostate cancer. J Nucl Med. 1996 Jun; 37(6): 999-1001. PMid:8683333.

[5] Sauerborn D, Vidakovic B, Baranovic M, et al. Gastric adenocarcinoma metastases to the alveolar mucosa of the mandible: a case report and review of the literature. J Craniomaxillofac Surg. 2011 Dec; 39(8): 645-8. PMid:21112790. http://dx .doi.org/10.10 $16 / j \cdot j \mathrm{cms} .2010 \cdot 10.020$

[6] Thobe MN, Clark RJ, Bainer RO, et al. From prostate to bone: key players in prostate cancer bone metastasis. Cancers (Basel). 2011; 3(1): 478-93. PMid:21603150. http://dx.doi.org/10.3390/c ancers 3010478
[7] Hirshberg A, Berger R, Allon I, et al. Metastatic tumors to the jaws and mouth. Head Neck Pathol. 2014 Dec; 8(4): 46374. PMid:25409855. http://dx.doi.org/10.1007/s12105-0 14-0591-z

[8] Aksoy S, Orhan K, Kursun S, et al. Metastasis of prostate carcinoma in the mandible manifesting as numb chin syndrome. World J Surg Oncol. 2014 Dec 29; 12: 401. PMid:25547947. http: //dx.doi.org/10.1186/1477-7819-12-401

[9] van der Waal RI, Buter J, van der Waal I. Oral metastases: report of 24 cases. Br J Oral Maxillofac Surg. 2003 Feb; 41(1): 3-6. http://dx.doi.org/10.1016/S0266-4356 (02) 00301-7

[10] Thatcher SL, Dye CG, Grau MJ, et al. Carcinoma of the prostate metastatic to the mandibular condyle mimicking a parotid tumor. $\mathrm{J}$ Oral Maxillofac Surg. 1986 May; 44(5): 394-7. http://dx.doi.o $\mathrm{rg} / 10.1016 / \mathrm{S} 0278-2391$ (86) 80036-2

[11] Catrambone RJ, Pfeffer RC. Significant postoperative hemorrhage following biopsy of a prostate tumor metastatic to the mandibular condyle: report of a case. J Oral Maxillofac Surg. 1990 Aug; 48(8): 858-61. http://dx.doi.org/10.1016/0278-2391 (90 ) $90346-4$

[12] Qiu YT, Yang C, Chen MJ, et al. Metastatic spread to the mandibular condyle as initial clinical presentation: radiographic diagnosis and surgical experience. J Oral Maxillofac Surg. 2013 Apr; 71(4): 80920. PMid:22921750. http://dx.doi .org/10.1016/j . joms . 20 12.07 .026 